\title{
НЕОБЫЧНЫЙ ДОСТОЕВСКОФИЛ
}

\author{
Всеволод Евгеньевич Багно - член- \\ корреспондент РАН, научный руково- \\ дитель Института русской литературы \\ (Пушкинский Дом) РАН, профессор \\ филологического факультета Санкт- \\ Петербургского государственного уни- \\ верситета. \\ Институт русской литературы (Пуш- \\ кинский Дом) РАН. Адрес: Российская \\ Федерация, 199034, Санкт-Петербург, \\ наб. Макарова, д. 4. \\ E-mail:vsbagno@gmail.com
}

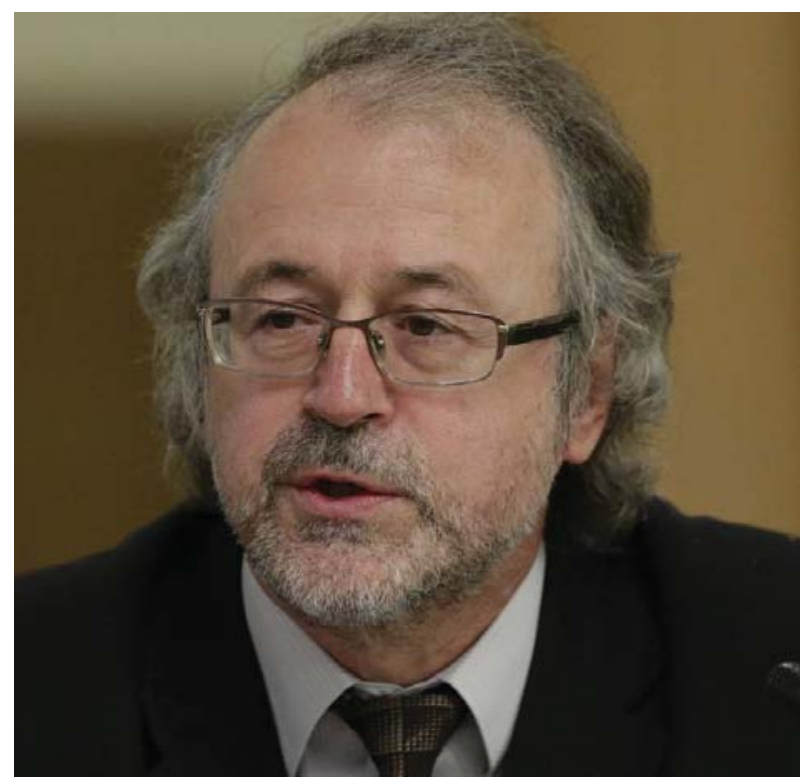

Аннотация. Публикация в русском переводе эссе «Необычный русофил» (1914) М. де Унамуно - отклик испанского философа и писателя на события Первой мировой войны, в которой Испания не принимала участия, - представляет большой научный интерес в связи с 200-летием со дня рождения Ф. М. Достоевского. «Необычность» испанского русофила состоит в том, что в споре о воюющих державах он становится на сторону России только потому, что голосует «за торжество духа», то есть за то представление и ощущение, которое от жизни и мира имел автор «Преступления и наказания».

Ключевые слова: М. де Унамуно, Первая мировая война, имагология, Ф. М. Достоевский

Благодарности: Работа, по результатам которой написана статья, выполнена при финансовой поддержке РФФИ в рамках научного проекта № 18-01290014 «Проблемы рецепции личности и творчества Достоевского в мировой культуре: история и современность».

Предисловие к публикации перевода эссе М. де Унамуно «Необычный русофил» включает отдельные положения статьи (Багно, 2020). 
Ссылка для цитирования: Багно В. Е. Необычный достоевскофил // Философические письма. Русско-европейский диалог. 2021. Т. 4, № 2. С. 108-112.

DOI: $10.17323 / 2658-5413-2021-4-2-108-112$

И спанский философ и писатель, предшественник экзистенциализма Мигель де Унамуно (1864-1936) - типичный представитель пограничных между Востоком и Западом культур, в разные годы напоминавший русских западников и русских славянофилов. В юности он переболел как социализмом, так и идеей «европеизации» Испании, а в зрелые годы предложил концепцию «испанизации» Европы, духовной экспансии Испании ${ }^{1}$.

Знаменательна принадлежность русской и испанской историософской мысли в ее русофильском и испанофильском изводах к одной и той же парадигме. Например, унамуновская теория интраистории, основанная на идеях вневременной, внеисторической действительности, неподвижности и самодостаточности материальной и духовной жизни, инаковости к поступательному движению мирового духа, во многом напоминает славянофильские и почвеннические доктрины.

Далеко не случайно в одном из писем Анхелю Ганивету, жившему и работавшему в Российской империи с 1892 по 1898 год в качестве сотрудника испанского консульства (Гельсингфорс и Рига), Унамуно признавался, что хотел бы знать «самое русское из русского, самое подлинное, самое исконное, наименее космополитическое» (Gallego Morell, 1971: 100).

Все это нелишне вспомнить, обращаясь к одному из многочисленных его эссе «Необычный русофил» (Unamuno, 1914) - отклику Унамуно на события Первой мировой войны, в которой Испания не принимала участия.

Сам мыслитель подчас высказывал идеи, напоминающие те, сторонником которых был его персонаж Необычный русофил. Любопытным свидетельством тому является назидание Ортеги-и-Гассета, высказанное им в одном из писем к Мигелю де Унамуно:

Я глубоко убежден, что вам следует сосредоточиться на объективном изучении явлений культуры <..>. Я бы приветствовал, если бы вы, для соблюдения духовной диеты, посвятили себя какой-нибудь сугубо научной проблематике. Да

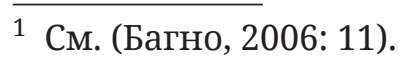


послужит вам «Моя вера» Толстого предостережением: я обратился к наукам и не нашел... в этом есть что-то семитское и антиевропейское.

(Ortega, Unamuno, 1987: 60)

Публикация этого эссе в русском переводе в связи с 200-летием со дня рождения Достоевского вполне объяснима: «необычность» испанского русофила состоит в том, что в споре о воюющих державах он становится на сторону России, поскольку выступает «за торжество духа, то есть за то представление и ощущение, которое от жизни и мира имел Достоевский» (Unamuno, 1966: IX, 1248).

Испанский философ никогда не включал автора «Преступления и наказания» в число писателей, оказавших на него непосредственное влияние ${ }^{2}$. Однако упоминания имени Ф. М. Достоевского в эссе и очерках, глубокие и разнообразные замечания о его творчестве, чрезвычайно близком Унамуно во многих отношениях, не оставляют сомнения в том, что романы русского писателя он прочел не без пользы для себя³

Удивительна и по-своему показательна общая трансформация в XX веке мировой культуры: после Первой мировой войны весь цивилизованный мир в идейных и эстетических поисках и пристрастиях переориентировался с актуального Толстого на более актуального для XX столетия Достоевского ${ }^{4}$. Одним из показательных подтверждений этому является эссе испанского философа.

Знаменательно не только то, что в своем эссе Унамуно предоставляет слово одному лишь русофилу, но и то, что в контексте споров аргументы русофила, точнее было бы сказать «достоевскофила», звучат наиболее убедительно.

\section{Литература}

Багно, 2006 - Багно B. E. Пограничные культуры между Востоком и Западом (Россия и Испания) // Багно В. Е. Россия и Испания: общая граница. СПб.: Наука, 2006. С. 5-20.

Багно, 2020 - Багно В. Е. Ясные поляны и петербургские углы России и русской литературы (Прогнозы и пророчества Э. Пардо Басан) // Русская литератуpa. 2020. № 3. C. 74-84. DOI: 10.31860/0131-6095-2020-3-74-84.

\footnotetext{
${ }^{2}$ Среди них он называл Гегеля, Шопенгауэра, Кьеркегора, Ибсена, Карлейля, Амьеля, Спенсера, Леопарди. В этом списке был и Л. Н. Толстой.

${ }^{3}$ О творческом усвоении М. де Унамуно наследия русских писателей и мыслителей, не только Толстого и Достоевского, но также Л. Н. Андреева, Н. А. Бердяева и Л. Шестова, см. (Корконосенко, 2002).

${ }^{4}$ См., напр., (Багно и др., ред., 2003).
} 
Корконосенко, 2002 - Корконосенко К. Мигель де Унамуно и русская культура. СПб.: Европейский Дом, 2002. 396 с.

Багно и др., ред., 2003 - Толстой или Достоевский? Философско-эстетические искания в культурах Востока и Запада. Материалы Международной конференции, 3-6 сент. 2001 г. / ред. В. Е. Багно и др. СПб.: Наука, 2003. 252 с.

Gallego Morell, 1971 - Gallego Morell A. Estudios y textos ganivetianos. Madrid, 1971. XVI, $214 \mathrm{p}$.

Ortega, Unamuno, 1987 — Ortega y Gasset J., Unamuno M. de. Epistolario completo Ortega - Unamuno. Madrid: El Arquero, 1987. 190 p.

Unamuno, 1914 - Unamuno M. de. Un extraño rusófilo // La Nación. 1914. 28 de octubre.

Unamuno, 1966 - Unamuno M. de. Un extraño rusófilo // Unamuno M. de. Obras completas en 9 tomos. Madrid: Escelicer, 1966. T. IX: Discursos y artículos. P. 12461251.

(C) Багно В. Е., 2021

\section{AN UNUSUAL DOSTOEVSKOPHILE}

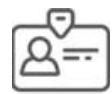

Vsevolod E. Bagno - Corresponding Member of the Russian Academy of Sciences; Academic Director, Institute of Russian Literature (Pushkinskij Dom), Russian Academy of Sciences; Professor, Department of Philology, St. Petersburg State University.

Institute of Russian Literature (Pushkinskij Dom), Russian Academy of Sciences. Address: 4 Makarova Embankment, St. Petersburg, 199034, Russian Federation.

E-mail: vsbagno@gmail.com

Abstract. "The Unusual Russophile”, published in 1914 by Miguel de Unamuno, Spanish philosopher and writer, was his response to the events of the First World War, in which Spain did not take part. The publication of the Russian translation of this essay in the year marked by F. M. Dostoevsky's bicentennial is of special scholarly interest. The "unusualness" of the Spanish russophile lies in the fact that he took the Russian side in the dispute about nations at war only because he stood for "the triumph of the spirit", i. e. for the idea and feeling that the author of "Crime and $\mathrm{Pu}$ nishment” had had from life and the world.

Keywords: M. de Unamuno, the First World War, Imagology, F. M. Dostoevsky 
Acknowledgements: The publication was carried out with the financial support of the RFBR in the framework of the scientific project No 18-012-90014 "Problems of reception of Dostoevsky's personality and creativity in World Culture: history and modernity".

For citation: Bagno, V.E., 2021. 'An Unusual Dostoevskophile', Philosophical Letters. Russian and European Dialogue, 4(2), pp. 108-112. (In Russ.)

DOI: $10.17323 / 2658-5413-2021-4-2-108-112$

\section{References}

Bagno, V.E., 2006. 'Pogranichnye kul'tury mezhdu Vostokom i Zapadom (Rossiya i Ispaniya)' ['Border cultures between East and West (Russia and Spain)'], in Bagno, V.E., Rossiya i Ispaniya: obshchaya granitsa [Russia and Spain: Common Border]. St. Petersburg: Nauka Publ., pp. 5-20.

Bagno, V.E., 2020. 'Yasniie Poliany and Petersburg Corners of Russia and Russian Literature (Prophesies and Prognostications of E. Pardo Bazán)', Russian Literature, (3), pp. 74-84. (In Russ.) doi: 10.31860/0131-6095-2020-3-74-84

Korkonosenko, K., 2002. Migel' de Unamuno i russkaya kul'tura [Miguel de Unamuno and Russian Culture]. St. Petersburg: Evropeiskii Dom Publ.

Bagno, V.E. et al. (eds), 2003. Tolstoi ili Dostoevskii? Filosofsko-esteticheskie iskaniya $v$ kul'turakh Vostoka i Zapada. Materialy Mezhdunarodnoi konferentsii, 3-6 sentyabrya 2001 goda [Tolstoy or Dostoevsky? Philosophical and Aesthetic Searches in the Cultures of the East and West. Proceedings of the International Conference, 3-6 September 2001]. St. Petersburg: Nauka Publ.

Gallego Morell, A., 1971. Estudios y textos ganivetianos [Ganivetian Studies and Texts]. Madrid.

Ortega y Gasset, J., Unamuno, M. de, 1987. Epistolario completo Ortega — Unamuno [Complete Epistolary Ortega - Unamuno]. Madrid: El Arquero Publ.

Unamuno, M. de, 1914. 'Un extraño rusófilo’ ['An Unusual Russophile’], La Nación, 28 October.

Unamuno, M. de, 1966. 'Un extraño rusófilo’ ['An Unusual Russophile’], in Unamuno, M. de., Obras completas en 9 tomos. T. IX: Discursos y artículos [Complete Works in 9 vols. Vol. IX: Speeches and articles]. Madrid: Escelicer Publ., pp. 1246-1251. 